\title{
A hydrologist's guide to open science
}

\author{
Caitlyn A. Hall ${ }^{1}$, Sheila M. Saia ${ }^{2}$, Andrea L. Popp ${ }^{3,4}$, Nilay Dogulu ${ }^{5}$, Stanislaus J. Schymanski ${ }^{6}$, Niels Drost ${ }^{7}$, \\ Tim van Emmerik $^{8}$, and Rolf Hut ${ }^{9}$ \\ ${ }^{1}$ The Honors College and Biosystems Engineering Department, University of Arizona, Tucson, AZ, USA \\ ${ }^{2}$ State Climate Office of North Carolina, North Carolina State University, Raleigh, NC, USA \\ ${ }^{3}$ Department of Geosciences, University of Oslo, Oslo, Norway \\ ${ }^{4}$ Hydrology Research, Swedish Meteorological and Hydrological Institute (SMHI), Norrköping, Sweden \\ ${ }^{5}$ Independent researcher, Ankara, Turkey \\ ${ }^{6}$ Catchment and Eco-hydrology research group (CAT), Department of Environmental Research and Innovation (ERIN), \\ Luxembourg Institute of Science and Technology (LIST), Belvaux, Luxembourg \\ ${ }^{7}$ Netherlands eScience Center, Amsterdam, the Netherlands \\ ${ }^{8}$ Hydrology \& Quantitative Water Management Group, Wageningen University, Wageningen, the Netherlands \\ ${ }^{9}$ Water Resources Section, Faculty of Civil Engineering and Geosciences, \\ Delft University of Technology, Delft, the Netherlands
}

Correspondence: Rolf Hut (r.w.hut@ $@$ tudelft.nl) and Caitlyn A. Hall (cahall@ arizona.edu)

Received: 22 July 2021 - Discussion started: 2 August 2021

Revised: 2 December 2021 - Accepted: 20 December 2021 - Published: 9 February 2022

\begin{abstract}
Open, accessible, reusable, and reproducible hydrologic research can have a significant positive impact on the scientific community and broader society. While more individuals and organizations within the hydrology community are embracing open science practices, technical (e.g., limited coding experience), resource (e.g., open access fees), and social (e.g., fear of weaknesses being exposed or ideas being scooped) challenges remain. Furthermore, there are a growing number of constantly evolving open science tools, resources, and initiatives that can be overwhelming. These challenges and the ever-evolving nature of the open science landscape may seem insurmountable for hydrologists interested in pursuing open science. Therefore, we propose the general "Open Hydrology Principles" to guide individual and community progress toward open science for research and education and the "Open Hydrology Practical Guide" to improve the accessibility of currently available tools and approaches. We aim to inform and empower hydrologists as they transition to open, accessible, reusable, and reproducible research. We discuss the benefits as well as common open science challenges and how hydrologists can overcome them. The Open Hydrology Principles and Open Hydrology Practical Guide reflect our knowledge of the current state of open hydrology; we recognize that recommendations and sugges-
\end{abstract}

tions will evolve and expand with emerging open science infrastructures, workflows, and research experiences. Therefore, we encourage hydrologists all over the globe to join in and help advance open science by contributing to the living version of this document and by sharing open hydrology resources in the community-supported repository (https: //open-hydrology.github.io, last access: 1 February 2022).

\section{Motivation for open hydrology}

Hydrologic research intersects various Earth sciences (e.g., climatology, geology, ecology) and social sciences (e.g., policy and public health) to tackle pressing environmental and societal challenges. Further, hydrologic research often incorporates qualitative and quantitative data from numerical models, laboratory techniques, field observations, and stakeholder surveys, all of which rely on separate sets of assumptions, standards, and methods. When combined, the interdisciplinary nature and wide range of methods used in hydrology can result in research that is neither accessible nor usable by the scientific community and relevant stakeholders. A recent study found that only $1 \%$ of hydrology papers were fully reproducible (Stagge et al., 2019). Therefore, hydrolo- 
gists must evolve to ensure their data and research process are transparent and reproducible. Doing so will strengthen their contribution to hydrologic research practices, educational resources, knowledge bases, and applications as well as educational resources, science, communication, societal engagement, and public trust (Cudennec et al., 2020). Open science outputs share scientific insights beyond those discussed in the main text of journal articles and are more accessible for more researchers, leading to an increase in citations (Piwowar et al., 2007). Another benefit of embracing open science practice is a vastly improved collaboration practice. The potential for being "scooped", or seeing your results or ideas published by someone else without proper acknowledgement of the origin, is reduced in an open science world because intermediate scientific results and ideas are placed in the public domain with clear authorship and date (Laine, 2017).

Open science offers an established framework for hydrologists to purposefully document and widely share scientific research that is accessible to scientists and the public so as to improve their work's transparency and reproducibility. Open science is a movement that is transforming the nature of research design and conduct as well as how experts and nonexperts alike build upon and learn from each other's work. Researchers, particularly in early career stages, and stakeholders are recognizing open science as the future of weather, climate, and water research, scientific communication, and education (Toribio-Flórez et al., 2021; Baker et al., 2020; UNESCO, 2021; WMO, 2021). Open science practices and tools satisfy needs brought by science and technology evolution and advancement as well as a rapidly growing interest in interdisciplinary collaboration (Ramachandran et al., 2021). Many Earth science disciplines, including hydrology, have cemented the demand and necessity for open science (Blumenthal et al., 2014; de Vos et al., 2020; Ferrari et al., 2018; Powers and Hampton, 2019; Tai and Robinson, 2018). There are even community-driven efforts entirely dedicated to open science in the form of research projects (e.g., Beck et al., 2020; Lowndes et al., 2017, Armeni et al., 2021) and conferences (e.g., OpenAIRE's Mission and Vision, 2021). Likewise, many organizations have begun to provide support, conference sessions, online repositories, and educational training opportunities to overcome challenges and support researchers as they transition to open science (Baker et al., 2020). Furthermore, several journals now require data and analyses to be made publicly available upon article publication (Rosenberg and Watkins, 2018; American Geophysical Union (AGU), 2019). In response to and as support for these calls and efforts, hydrological sciences have been progressing towards open science. Table 1 provides a summary of various hydrology-focused efforts towards open science (e.g., academic articles, GitHub pages, web platforms).

Despite general calls and efforts to support open science, practical guidance on steps hydrologists can take to incorporate open science principles into their research is limited. Open science shifts the focus to improving research's repro- ducibility, transparency, collaboration and source acknowledgement, and long-term impact, not unlike calls for "slow science" (Frith, 2020). These shifts in priorities necessitate new approaches to assessing one's own research, like following the San Francisco Declaration on Research Assessment (DORA; sfdora.org) and adapting accordingly. However, the time and effort required to adjust one's research practice and learn new techniques may seem daunting and in conflict with academia's current drive to increase its productivity and output quantity (i.e., the "publish or perish mentality") (Zuiderwijk et al., 2020). We also recognize that the level of incorporating open science into their research, access to resources, and how barriers are experienced and overcome varies by researcher and location (Mwela et al., 2020).

The objective of this paper is to introduce the Open Hydrology Principles and Open Hydrology Practical Guide to help hydrologists take actionable steps towards open science. We focus on four major research stages: (1) research process and approach, (2) data collection and analysis, (3) code and software use and development, and (4) publishing. For each stage, we discuss guiding principles for meaningful engagement in open hydrology and we provide practical steps to answer how to engage in openness. Table 2 summarizes tips, tools, and resources for each principle. Finally, we address potential challenges by walking through "What if...?" questions that hydrologists might encounter when pursuing open science (Appendix A). Herein, we draw on existing open science research, efforts, and experiences in hydrology as well as in disciplines outside of hydrology that have made significant progress toward open science. The Open Hydrology Principles and Open Hydrology Practical Guide are also available online at https://open-hydrology.github.io (last access: 1 February 2022). This website provides a platform to facilitate continued discussion and evolution of open hydrology presented in this article (i.e., to serve as a living document), highlight emerging open hydrology resources and educational opportunities, and serve as a meeting point to connect open hydrologists. We invite everyone to contribute to the discussion, share resources and experiences, and work towards incorporating open science principles into all stages of their hydrology research.

\section{Open Hydrology Principles and Open Hydrology Practical Guide}

Open hydrologists, including those who are beginning their journey and those who are more experienced, can use the Open Hydrology Principles and Open Hydrology Practical Guide to expand their open hydrology practice. Adoption of these open hydrology principles is not restricted to a specific stage of research. Furthermore, these principles can and should be implemented throughout a research project's timeline. Transitioning to fully open hydrology research will likely remain a work in progress and cannot hap- 
Table 1. A selection of efforts that discuss and support openness in hydrology and related sub-disciplines ( ${ }^{a}$ peer-reviewed article, $\mathrm{b}$ community contribution). For an up-to-date resource list, see https://open-hydrology.github.io/resources/ (last access: 1 February 2022).

\begin{tabular}{|c|c|c|}
\hline Theme & Title & Reference \\
\hline \multirow[t]{7}{*}{ General } & The Tao of open science for ecology ${ }^{a}$ & Hampton et al. (2015) \\
\hline & Enhancing Climate Change Research With Open Science ${ }^{\mathrm{a}}$ & Tai and Robinson (2018) \\
\hline & Open weather and climate science in the digital era ${ }^{\mathrm{a}}$ & de Vos et al. (2020) \\
\hline & Cracking "Open” Technology in Ecohydrology ${ }^{a}$ & Turner et al. (2020) \\
\hline & The importance of open science for biological assessment of aquatic environments ${ }^{\mathrm{a}}$ & Beck et al. (2020) \\
\hline & Open Hydrology Website (established with this paper) & $\begin{array}{l}\text { https://open-hydrology.github.io/ } \quad(1 \text { Febru- } \\
\text { ary 2022) }\end{array}$ \\
\hline & $\begin{array}{l}\text { HydroShare is CUAHSI's online collaboration environment for sharing data, models, } \\
\text { and code. }\end{array}$ & HydroShare (2021) \\
\hline \multirow[t]{4}{*}{ Open publishing } & Joint Editorial - On the future of journal publications in hydrology ${ }^{\mathrm{a}}$ & Blöschl et al. (2014) \\
\hline & Improving the visibility of hydrological sciences from developing countries ${ }^{\mathrm{a}}$ & Hughes et al. (2014) \\
\hline & $\begin{array}{l}\text { Assessing data availability and research reproducibility in hydrology and water } \\
\text { resources }^{\text {a }}\end{array}$ & Stagge et al. (2019) \\
\hline & Invigorating Hydrological Research Through Journal Publications ${ }^{\mathrm{a}}$ & Quinn et al. (2020) \\
\hline \multirow{12}{*}{$\begin{array}{l}\text { Open source and } \\
\text { reproducibility }\end{array}$} & Most computational hydrology is not reproducible, so is it really science? ${ }^{\mathrm{a}}$ & Hutton et al. (2016) \\
\hline & $\begin{array}{l}\text { Comment on "Most computational hydrology is not reproducible, so is it really sci- } \\
\text { ence?" }\end{array}$ & Melsen et al. (2017) \\
\hline & Towards a more reproducible ecology ${ }^{a}$ & Borregaard and Hart (2016) \\
\hline & Elevating The Status of Code in Ecology ${ }^{a}$ & Mislan et al. (2016) \\
\hline & Using R in hydrology: a review of recent developments and future directions ${ }^{a}$ & Slater et al. (2019) \\
\hline & Hydrogeological conceptual model building and testing: A review ${ }^{\mathrm{a}}$ & Enemark et al. (2019) \\
\hline & Open science, reproducibility, and transparency in ecology ${ }^{a}$ & Powers and Hampton (2019) \\
\hline & $\begin{array}{l}\text { On doing large-scale hydrology with Lions: Realising the value of perceptual models } \\
\text { and knowledge accumulation }{ }^{b}\end{array}$ & Wagener et al. (2021) \\
\hline & Current status on the need for improved accessibility to climate models code ${ }^{a}$ & Añel et al. (2021) \\
\hline & Created for EGU GA short course "Using R in Hydrology"b & Young Hydrologic Society (YHS) (2021) \\
\hline & $\begin{array}{l}\text { "a specific list of open hydrology-relevant projects. This list is curated from repositories } \\
\text { that make our lives as (eco-)hydrologists easier."b }\end{array}$ & $\begin{array}{l}\text { https://github.com/ } \\
\text { Open-Environmental-Science/ } \\
\text { awesome-open-hydrology (last access: } \\
1 \text { February 2022) }\end{array}$ \\
\hline & $\begin{array}{l}\text { Hydrological Data and Modeling in R. This initiative was built on the EGU GA short } \\
\text { course "Using R in Hydrology"b }\end{array}$ & ropensci/Hydrology: CRAN Hydrology (2021) \\
\hline \multirow[t]{4}{*}{ Open data } & Challenges and Opportunities of Open Data in Ecology ${ }^{a}$ & Reichman et al. (2011) \\
\hline & $\begin{array}{l}\text { Ecological data sharing }^{\mathrm{a}} \\
\text { Editorial - Towards FAIR and SQUARE hydrological data }\end{array}$ & $\begin{array}{l}\text { Michener (2015) } \\
\text { Cudennec et al. (2020) }\end{array}$ \\
\hline & $\begin{array}{l}\text { Large-sample hydrology: recent progress, guidelines for new datasets and grand chal- } \\
\text { lenges }\end{array}$ & Addor et al. (2020) \\
\hline & $\begin{array}{l}\text { Lessons learnt from checking the quality of openly accessible river flow data } \\
\text { worldwide }^{\mathrm{a}}\end{array}$ & Crochemore et al. (2020) \\
\hline \multirow[t]{5}{*}{ Open education } & Educational Resources for Hydrology and Water Resources ${ }^{b}$ & $\begin{array}{l}\text { Educational Resources for Hydrology and Wa- } \\
\text { ter Resources: CUAHSI HydroShare }(2021)\end{array}$ \\
\hline & A buffet of new resources for teaching hydrology and water resources! ${ }^{b}$ & Gleeson (2020) \\
\hline & $\begin{array}{l}\text { Online teaching in courses related to climate risk, drought, water resources and } \\
\text { sustainability }{ }^{b}\end{array}$ & Van Loon (2020) \\
\hline & When the students are gone: Transition to online teaching ${ }^{b}$ & Sprenger (2020) \\
\hline & Open teaching to navigate hydrology: how ready are we ${ }^{b}$ & Schaefli (2021) \\
\hline
\end{tabular}


Table 1. Continued.

\begin{tabular}{|c|c|c|}
\hline Theme & Title & Reference \\
\hline \multirow[t]{6}{*}{ Data exchange } & $\begin{array}{l}\text { Barriers to the exchange of hydrometeorological data in Europe: Results from a survey } \\
\text { and implications for data policy }\end{array}$ & Viglione et al. (2010) \\
\hline & Balancing Open Science and Data Privacy in the Water Sciences ${ }^{\mathrm{a}}$ & Zipper et al. (2019) \\
\hline & Intergovernmental cooperation for hydrometry - what, why and how? ${ }^{\mathrm{a}}$ & Dixon et al. (2020) \\
\hline & E-monitoring the nature of water ${ }^{a}$ & Pecora and Lins (2020) \\
\hline & The devil's in the details: data exchange in transboundary waters ${ }^{\mathrm{a}}$ & Mukuyu et al. (2020) \\
\hline & $\begin{array}{l}\text { "Hydrological data and WMO Data Policy", in November 2020, as part of the WMO } \\
\text { Data Conference }\end{array}$ & WMO Unified Data Policy Resolution (2021) \\
\hline
\end{tabular}

pen overnight. Hydrologists will need to work within current logistical, legal, financial, cultural, and other constraints. In this section, we outline four guiding principles corresponding to four major hydrological research stages illustrated in Fig. 1. Each guiding principle is followed by a practical guide to help hydrologists apply these principles. We have also included a discussion on anticipating and overcoming challenges to practicing open hydrology (Appendix A), which can be used for educational purposes as well as spurring discussion and action in open hydrologists of all levels and in various settings from classrooms to lab groups to workshops.

\subsection{Principle 1 - open research process and approach: open hydrologists intentionally plan for, describe, and share the entire research process and approach from motivation to final output}

Research process and approach include openly discussing stakeholder engagement practices and agreements, failed methods, negative results, use of public datasets, and feedback from third parties. Openly sharing a well-documented research process and approach hydrology will improve the efficacy of internal research and knowledge exchange and give critical insight to aspiring researchers that may not be fully captured in journal articles. Furthermore, sharing the entire research process and approach is ideal for the hydrology discipline because research applications directly impact society (e.g., water management, climate change and adaptation). Thus, open hydrologists must ensure their research is accessible to the science community and the general public while adhering to ethical standards and respecting the goals and wishes of their collaborators. We encourage the use of non-proprietary methods, tools, and resources whenever possible.

\section{Practical guide to open research process and approach}

In hydrology, published studies that allow the reader to follow every step of the work, from motivation to publication, remain scarce. Although results are the main focus of a paper, sharing the entire research process and approach (e.g., failed attempts and lessons learned that impacted research outcomes) as appropriate in the main journal article and in detail in the Supplement section can improve the impact and openness of research (Lowndes et al., 2017; Colavizza et al., 2020). An additional option for authors is to share the entire research process associated with a publication through the Open Science Foundation's platform (https://osf.io/, last access: 1 February 2022). We suggest including a reasonable explanation of why certain data and methods were chosen and how they were used in the main text of journal articles or an appendix using accessible language, as is possible. Open hydrologists can maximize openness by minimizing the use of jargon in all materials such that experts and non-experts alike are able to understand and reproduce the research and underlying assumptions. For example, words common in hydrology like "dam" and "flood" can have different meanings between experts and non-experts (Venhuizen et al., 2019). When this is not possible, jargon and niche terms should be defined to (1) describe a unique process and (2) ensure that a word with multiple interpretations is defined (e.g., "substrate" meaning something you feed bacteria versus "substrate" meaning soil). Open hydrologists can consider getting feedback on the accessibility of the research process and approach description by sharing drafts with collaborators and stakeholders.

Perceptual models are in-depth descriptions or visualizations that represent process understanding, qualitative and quantitative data incorporation, field-, lab-, or computerbased methods and protocols, and project stages, also known as a workflow model (Enemark et al., 2019; Wagener et al., 2021). Perceptual models help researchers decide and describe which methods are most appropriate to address the study objective based on underlying assumptions. Consequently, perceptual models will vary by researcher, information, and resource availability. By including accessible perceptual models, researchers can communicate differences in the interpretation and understanding of hydrologic systems while identifying dominant hydrologic processes across scales and experiment types. Moreover, such models explicitly handle uncertainties and failures during the research process and provide a coherent picture of the entire research process to experts and non-experts (Wagener et al., 2021). 
Table 2. Summary of tips, tools, and resources for the Open Hydrology Principles and Practical Guide.

\begin{tabular}{|c|c|c|c|c|}
\hline & $\begin{array}{l}\text { Principle 1: } \\
\text { open research process and approach }\end{array}$ & $\begin{array}{l}\text { Principle 2: } \\
\text { open data collection and analysis }\end{array}$ & $\begin{array}{l}\text { Principle } 3 \text { : } \\
\text { open code, software development, } \\
\text { and use }\end{array}$ & $\begin{array}{l}\text { Principle } 4 \text { : } \\
\text { open publishing }\end{array}$ \\
\hline $\begin{array}{l}\text { Principle } \\
\text { description }\end{array}$ & $\begin{array}{l}\text { Open hydrologists intentionally plan } \\
\text { for, describe, and share the entire re- } \\
\text { search process and approach from } \\
\text { motivation to the final output. }\end{array}$ & $\begin{array}{l}\text { Open hydrologists document all } \\
\text { components of their data collection } \\
\text { and analysis pipeline, favoring open } \\
\text { and non-proprietary technologies. }\end{array}$ & $\begin{array}{l}\text { Open hydrologists test, archive, doc- } \\
\text { ument, and version control their re- } \\
\text { search code and software using stan- } \\
\text { dard open source software protocols } \\
\text { and accessible documentation lan- } \\
\text { guage. }\end{array}$ & $\begin{array}{l}\text { Open hydrologists publish all com- } \\
\text { ponents of their research on citable } \\
\text { platforms and in journals that follow } \\
\text { ethical standards and are accessible } \\
\text { to both the research community and } \\
\text { general public. }\end{array}$ \\
\hline Do's/tips & $\begin{array}{l}\text { - Describe your research process } \\
\text { from idea formulation to final } \\
\text { outputs. } \\
\text { - Include a perceptual model and } \\
\text { explain why certain data and } \\
\text { methods were chosen. } \\
\text { - Minimize the use of jargon. } \\
\text { - Make your research FAIR } \\
\text { (findable, accessible, interop- } \\
\text { erable, reproducible). } \\
\text { - Follow CARE (collective ben- } \\
\text { efit, authority to control, re- } \\
\text { sponsibility, ethics) principles } \\
\text { when applicable. }\end{array}$ & $\begin{array}{l}\text { - Store raw and processed data } \\
\text { and metadata in software- } \\
\text { agnostic, non-proprietary } \\
\text { formats. } \\
\text { - Detail data collection methods } \\
\text { (including hardware) and anal- } \\
\text { ysis workflow. } \\
\text { - Make a data management plan } \\
\text { using open data management } \\
\text { tools. } \\
\text { - Provide access to all data and } \\
\text { related information necessary } \\
\text { to reproduce your study. } \\
\text { - Justify why data cannot be } \\
\text { shared publicly and/or must re- } \\
\text { main private. } \\
\text { - Describe how one could obtain } \\
\text { data, if not easily accessible. }\end{array}$ & $\begin{array}{l}\text { - Use open source programming } \\
\text { languages, software, and plat- } \\
\text { forms. } \\
\text { - Use version control software } \\
\text { and document changes made } \\
\text { in a clear and comprehensible } \\
\text { way. } \\
\text { - Detail your computational en- } \\
\text { vironment (e.g., package ver- } \\
\text { sions) and workflows (e.g., } \\
\text { what order to run data process- } \\
\text { ing scripts) to enable repro- } \\
\text { ducibility. }\end{array}$ & $\begin{array}{l}\text { - Publish in open access jour- } \\
\text { nals. } \\
\text { - Check online preprint policies, } \\
\text { copyrights, and open access } \\
\text { archiving policies from various } \\
\text { publishers and journals. } \\
\text { - Use preprint servers to docu- } \\
\text { ment your work for record and } \\
\text { community input. } \\
\text { - Use open repositories to ensure } \\
\text { research material accessibility. } \\
\text { - Advocate open science prac- } \\
\text { tices when reviewing papers } \\
\text { (e.g., requiring proper data or } \\
\text { code citation). }\end{array}$ \\
\hline $\begin{array}{l}\text { Tools and } \\
\text { resources }\end{array}$ & $\begin{array}{l}\text { - Open planning and scien- } \\
\text { tific collaboration tools: e.g., } \\
\text { Jupyter notebooks, Github, } \\
\text { Google Drive, Open Lab } \\
\text { Notebooks } \\
\text { - Research process sharing: e.g., } \\
\text { Open Science Foundation Plat- } \\
\text { form (OSF) } \\
\text { - "On doing hydrology with } \\
\text { dragons: Realizing the value of } \\
\text { perceptual models and knowl- } \\
\text { edge accumulation" by Wa- } \\
\text { gener et al. (2021) } \\
\text { - "The CARE Principles for In- } \\
\text { digenous Data Governance" by } \\
\text { Carroll et al. (2020) } \\
\text { - "The FAIR Guiding Principles } \\
\text { for scientific data management } \\
\text { and stewardship" by Wilkin- } \\
\text { son et al. (2016) } \\
\text { - "The importance of open sci- } \\
\text { ence for biological assessment } \\
\text { of aquatic environments" by } \\
\text { Beck et al. (2020) }\end{array}$ & $\begin{array}{l}\text { - Data management systems: } \\
\text { e.g., Data Management Plan- } \\
\text { ning Tool (DMPTool), ckan } \\
\text { - Reproducible data analysis } \\
\text { pipelines: e.g., RenkuLab, } \\
\text { rOpenSci } \\
\text { - Metadata standards: digital cu- } \\
\text { ration standards } \\
\text { - Education and training: the } \\
\text { Carpentries } \\
\text { - "The Tao of open science for } \\
\text { ecology" by Hampton et al. } \\
\text { (2015) } \\
\text { - "A Guide and Toolbox to } \\
\text { Replicability and Open Sci- } \\
\text { ence in Entomology" by } \\
\text { Wittman and Aukema (2010) } \\
\text { - "Principles for data analysis } \\
\text { workflows" by Stoudt et al. } \\
\text { (2021) }\end{array}$ & $\begin{array}{l}\text { - Programming languages: e.g., } \\
\text { R, Python } \\
\text { - Integrated development envi- } \\
\text { ronments: e.g., RStudio, Spy- } \\
\text { der } \\
\text { - Computational notebooks: } \\
\text { e.g., Jupyter notebooks, R } \\
\text { Markdown } \\
\text { - Version control: e.g., Git, Git- } \\
\text { Lab, Subversion } \\
\text { - Software repositories: GitHub, } \\
\text { CRAN, PyPI, Bitbucket } \\
\text { - Data curation and replica- } \\
\text { ble analysis: Data Carpentry, } \\
\text { Happy R with Git, Docker } \\
\text { - Technical support: StackOver- } \\
\text { flow } \\
\text { - Documentation: readthedocs } \\
\text { - "Technical note: Hydrology } \\
\text { modelling R packages - a uni- } \\
\text { fied analysis of models and } \\
\text { practicalities from a user per- } \\
\text { spective” by Astagneau et al. } \\
\text { (2021) } \\
\text { - "Our path to better science in } \\
\text { less time using open data sci- } \\
\text { ence tools" by Lowndes et al. } \\
\text { (2017) }\end{array}$ & $\begin{array}{l}\text { - Public archival repositories: } \\
\text { Zenodo, figshare, Dryad } \\
\text { - Preprint server lists: ASAPbio, } \\
\text { re3data, Nature } \\
\text { - Information on preprint poli- } \\
\text { cies, copyrights, and open ac- } \\
\text { cess archiving policies from } \\
\text { various publishers and jour- } \\
\text { nals: Sherpa Romeo, Journal } \\
\text { Checker Tool (by cOAlition } \\
\text { S), Creative Commons, Open } \\
\text { Source Initiative } \\
\text { - "An Introduction to Preprints } \\
\text { for Early Career Hydrologists" } \\
\text { by Saia (2019) } \\
\text { - "Open Science: Open Data, } \\
\text { Open Models, ... and Open } \\
\text { Publications?" by Clark et al. } \\
\text { (2021) }\end{array}$ \\
\hline
\end{tabular}

Given the important societal and policy implications of hydrologic research, it is important for open hydrologists to codevelop data management plans, research focus, and research dissemination plans alongside stakeholders as early as possible in the research process. Stakeholders usually include fel- low researchers but may also include industry professionals, non-profit organizations, government officials, communities, members of the public, and other parties that have an interest in hydrologic research (Zuiderwijk and Hinnant, 2019). Engagement and co-development with stakeholders are still 


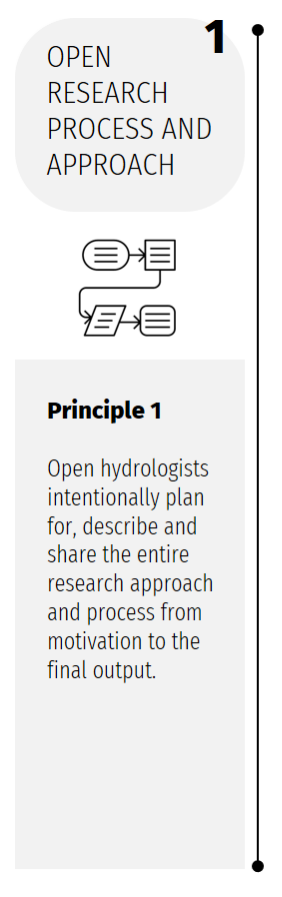

Figure 1. The Open Hydrology Principles.

limited in the field of hydrology. For example, a global survey found that $87 \%$ of climate research that engaged Indigenous communities was extractive: communities had minimal participation or decision-making authority in the researcherstakeholder relationship (David-Chavez and Gavin, 2018). Consequently, we suggest incorporating findable, accessible, interoperable, and reusable (FAIR - Wilkinson et al., 2016) and, where applicable, collective benefit, authority to control, responsibility, and ethics (CARE - Carroll et al., 2020) data standards into open hydrology research (Walter et al., 2020). FAIR data standards were developed to improve access to data and machine readability of data for the advancement of research and reproducibility. Thus, FAIR was aimed mainly at fellow researchers as stakeholders. CARE data standards were developed by Indigenous scholars to advance data governance and data sovereignty, such that community interests were considered whenever connected with a dataset. Thereby, CARE data standards encompass a greater variety of stakeholders. Setting up guidelines on how open hydrologists will ethically and respectfully engage with relevant stakeholders in their research approach and process is especially important when co-developing and conducting community science or citizen science (Robinson et al., 2018; Walker et al., 2021).

\subsection{Principle 2 - open data collection and analysis: open hydrologists document all components of their data collection and analysis pipeline, favoring open and non-proprietary technologies}

Hydrologists often combine data from a wide variety of field, laboratory, and computer sources, such as streamflow gauges, water samples, remote sensing datasets, digital elevation models, land use maps, and meteorological data. Data quality can only be assessed and potential results replicated when the hardware design and specifications of measurement tools and data loggers are available to the public. We encourage use of open (i.e., non-proprietary) data formats, hardware specifications, and software in data collection and processing workflows and their systematic documentation with the aim of enabling their re-use by the interested reader.

Data from the laboratory are often exported in formats specific to the laboratory device and typically require some data reformatting necessary for post-processing. The format of computer-generated data (e.g., hydrology model outputs) varies with the computer software that generated them. An open data collection and analysis pipeline includes information on (1) the hardware and software used, (2) original and processed (meta-)data and databases, (3) data processing and analysis techniques and tools used, and (4) documentation of the overall analysis process, including assumptions and perceptual models (see Principle 1). Re-usability and transferability of software and data processing pipelines greatly accelerate scientific progress in hydrology by reducing time wasted on re-inventing the wheel, helping discover problems 
in the analysis and improving the quality of hydrologic research.

\section{Practical guide to open data collection and analysis}

Open hydrologists share and cite the source and collection method of all qualitative and quantitative data involved in their research, including field, laboratory, computer, and/or third-party (online) data used. A current list of data repositories commonly used by hydrologists that adhere to open science standards is kept on https://open-hydrology.github.io, (last access: 1 February 2022). The best place to store data for an open hydrology project depends on the type and size of the data, the specific scientific domain, and other requirements stipulated by the funders and stakeholders. If an open hydrology study relies on third-party data that are not (yet) open, ask the original data creators to make the data or a data subset publicly available. Archived original, intermediate, and final versions of all data used to obtain the results of a particular study are crucial for reproducing open hydrology research. See Principle 4 for more details on publishing data.

To make data and analysis sharing more straightforward, a data management plan should be developed in the early stages of the research project, emphasizing open data principles and maintaining cyberinfrastructure and community standards. Data management plans describe where data will come from, which formats it will be stored in, who will manage and maintain them, how privacy will be maintained (if applicable), and how data and results will be shared and stored in the short and long term. Data management plans may be required by funders where they are typically limited in length. However, extended data management plans can increase research project transparency and can be created using publicly available templates (e.g., ckan, DMPTool, http://resources.data.gov/, last access: 1 February 2022) that adhere to funder requirements and formatting. Some tools (e.g., ckan) can help hydrologists make previously unpublished data publicly available, even after publication.

Open hydrologists explicitly provide public access (e.g., through a link accessible on the journal publication site) to (1) raw data and associated metadata (including specifications of the devices used to collect data), (2) descriptions and citations for the analysis methods and software versions used, (3) workflows, code, and software developed to collect and analyze data, (4) descriptions of quality controls used when processing raw data, (5) final processed data, and (6) descriptive methods used to integrate data into other processing tools. The level of detail necessary to ensure openness can differ wildly between studies, but the workflow for data-intensive research should be clear and reproducible (Stoudt et al., 2021). When data sources, processing, and accessibility are complex, additional descriptions in an Appendix or Supplement may be appropriate upon publication of hydrologic research. Open hydrologists also incorporate the use of open source, reusable, and reproducible data anal- ysis pipeline tools (e.g., renkulab.io, ropensci.org), which facilitate collaboration for data producers, analysts, and stakeholders.

Ideally, all data used to draw conclusions should be published publicly to facilitate reproducibility, but copyright on third-party data, privacy, or other issues related to data sensitivity may prohibit open publication of all underlying data. Discuss, agree, and document with your collaborators what can be shared publicly as early as possible. If certain datasets cannot be shared publicly, add a statement to the final publication explaining which conditions need to be fulfilled to obtain access to the data and why some data remain private. Relevant resources and local guidelines for data anonymization and sharing (e.g., General Data Protection Regulation) need to be considered before developing a data management plan and conducting research (Zipper et al., 2019). When making data publicly available, open hydrologists strive to store data in universal, non-proprietary, and software-agnostic formats that are compatible with most operating systems and include metadata (data about the data that provide background context). For example, text and tabulated data can be stored as standard American Standard Code for Information Exchange (ASCII) text instead of proprietary or software-specific types (e.g., Microsoft Word .docx or Excel .xlxs files) that require a paid software license to use. Even if it might be computationally efficient, avoid creating new file types that are specific to a certain model or software. For most hydrologic data, NetCDF (i.e., .nc) files are currently the gold standard for storing data and metadata. If metadata cannot be part of the data (file) themselves, store the metadata in as close a proximity to the data as possible. For example, open hydrologists can include links in the metadata to where the data are stored and vice versa. They can also use standard naming and unit conventions (e.g., SI units) and metadata formats following metadata standards based on application and topic and be informative and sufficiently complete to allow for better understanding of the data and reproduction of study results.

\subsection{Principle 3 - open code, software development, and use: open hydrologists test, archive, document, and version control their research code and software using standard open source software protocols and accessible documentation language}

Hydrologic research often relies on the use of computational models and research software, which must be archived with appropriate documentation and publicly accessible for verifiability and reproducibility of results. Research software is any code or program used to compile, filter, and process data, create model simulations, and generate data tables or plots. This includes compiled programs, stand-alone and embedded scripts (e.g., in spreadsheets), and computational notebooks (e.g., Jupyter notebooks, RMarkdown documents). Open hydrologists document and describe code, software versions, 
and descriptions of each variable name, meaning, and unit when developing software. Whenever possible, open hydrology software builds on existing open source software and programming languages (e.g., Python and R) to avoid excessive licensing and setup costs for anyone trying to use these models. Even more important than version tracking is depositing the code used for each publication in an open repository, further detailed in Principle 4.

To prevent duplication of failed attempts and increase accessibility and reproducibility, it is crucial to document the complete version history of software development in a clear and comprehensible way using standardized version tracking and version control tools (e.g., Git and Subversion SVN). This is particularly important in hydrology, which relies heavily on testing continuous adaptations of existing models as new data become available. Transparent version control, software documentation, software guides, and software unit tests are all prerequisites for producing trustworthy hydrologic model outputs and including predictions of future water resource availability and hydrologic risk. For software licensing and publishing, see Principle 4.

\section{Practical guide to open code, software development, and use}

Open platforms offer an effective way for open hydrologists to develop and use research software by building upon models and software created by others and getting community support. Open hydrologists can use open source coding languages (e.g., R and Python) and open source software (e.g., QGIS) to wrangle, analyze, and share their research findings. Repositories such as GitHub, GitLab, and Bitbucket and language-specific repositories such as CRAN and PyPI are treasure troves of software, often aggregating software for most research analysis needs. Using these public and open repositories saves you time and allows others to make use of your software more easily, help you improve it, and in turn build on it for your research.

In addition to open source coding languages and software, hydrologists can incorporate open source version control systems (e.g., Git) into their workflows to capture and manage changes made to code and research. Additionally, file duplication and mistakenly overwriting previous work can be prevented while allowing others to trace the progression of code, track issues, and collaborate (Perez-Riverol et al., 2016; Lowndes et al., 2017; Bryan, 2018). While the command-line application form of version control systems can pose a steep learning curve, graphical user interfaces exist and public repositories (e.g., Git Desktop, Git Cola, and GitKraken) offer easy-to-use interfaces, helpful documentation, and tutorials. Various courses are available through The Carpentries, a community of instructors committed to teaching foundational data science skills. The Carpentries can help you get started using Git and online Git collaboration platforms like GitHub and GitLab on topics including version control with Git (The Carpentries, 2022). These public repositories facilitate collaborative software development and issue tracking, detailed documentation of modeling decisions, and project management.

Documenting the workflow of software, from how to input data to how to interpret results, helps lower barriers for users (Pianosi et al., 2020). The simplest way of creating code documentation is often to include it with the software in some form, but technical documentation can also be hosted on Readthedocs. Variables need to be clearly defined, and documentation must include the units directly in the code or in an associated appendix. Various open source programming languages offer ways of generating technical documentation from the code itself (e.g., pydoc for Python and roxygen for $\mathrm{R})$. In addition to documenting the use of code, open hydrologists developing software should include inline comments to document the expected function of their code and relevant links to the literature. This not only improves transparency and code reuse in different contexts, but also provides students with instructive examples of real-world coding applications and software development.

Even if the source code of all packages used in a research project is publicly available, it may be difficult to reproduce an analysis if the versions of the packages are not known or if the operating system version is not compatible (Pianosi et al., 2020). For this reason, several methods for sharing a computational environment have been created in recent years. Software containers (e.g., Docker) can help to share a complete computational environment, including the operating system and necessary packages with your code (Nüst et al., 2020). Open source programming languages can also offer specific tools to keep track of versions (e.g., renv and Docker for $\mathrm{R})$. Other open source software platforms of interest to open hydrologists may include binder, which reproduces a computational Jupyter notebook with a single click from a software repository. Additionally, RenkuLab allows version control of data, software, and computational environments from within a single platform. RenkuLab also enables transparent tracking of the lineage of research results, from external data sources to final figures in articles, and includes reproduction of data analysis workflows in a continuous integration framework.

When using a GitHub repository, automatic code and software testing can be implemented using continuous integration software (e.g., Travis CI, GitHub Actions), which runs pre-designed tests and workflows and checks for errors. Tests and workflows may include comparing model results in a reference dataset, and alerting the user to changes in the model results or checking whether recent changes made to one section of code will cause errors in the downstream code. 


\subsection{Principle 4 - open publishing: open hydrologists publish all components of their research on citable platforms and in journals that follow ethical standards and are accessible to both the research community and general public}

Research sharing is pivotal to enabling the transferability of hydrologic insights and building on existing hydrology research. Thus, we strongly suggest open hydrologists publish all research components using an open license that allows editing and sharing of derivative works with both scientists and the general public. There are, however, special cases where information (e.g., from water utility providers or governmental agencies) cannot be shared publicly for privacy and safety (i.e., national security) reasons. If this is the case, the potential reproducibility limitations associated with these data need to be considered and openly discussed.

How and where open hydrologists choose to publish their work is crucial for supporting high global standards for the accessibility, preservation, and reproducibility of hydrology research. Whenever possible, open hydrologists publish all their results (including articles, data, and software) in publicly accessible repositories and journals with transparent connections between each (i.e., adding a link to the publication that points readers to the associated data and analysis code). It is also important that publishers and libraries have the appropriate infrastructure in place for bibliographic tracking, transparent cross-referencing between hosted research objects, and appropriate crediting of researchers for their contributions.

\section{Practical guide to open publishing}

There are three primary open access (OA) journal publication models: (1) gold OA or diamond OA, which provide free final typeset article access to everyone, (2) hybrid OA, which involves subscription-based journals that charge an additional fee for making a particular article freely accessible, and (3) green $\mathrm{OA}$, in which the reviewed postprint version of the manuscript (i.e., not the final typeset version) is shared with the public (Clark et al., 2021; van den Ende et al., 2021). Gold OA journals charge no subscription fees but typically require an article processing charge (APC) fee. Diamond OA journals do not charge an APC and are usually funded by non-profit organizations, governments, societies, or other revenue streams. The copyright for articles published in gold or diamond OA journals stays with the authors, whereas hybrid OA may provide the option that authors pay for obtaining the copyright on an individual article (in its final, typeset version) and for making it OA on the publisher's website. There are some exceptions to this for lead and/or corresponding authors working for government agencies where the general public is directly supporting their research; however, authors must check with the specific copyright policy of the journal for more details. In subscription-based green OA models, authors can self-archive the accepted, non-typeset authors' version of an article (i.e., a postprint) in a repository of the authors' choice after the journal's embargo period. However, this version may not be as accessible to read (e.g., figures separated from their reference in a paper) as the final typeset version. Hybrid publishing has been criticized because the scientific community typically pays twice - once for the journal subscription and once for individual article OA fees (Pinfield et al., 2016).

There are numerous aspects to consider when choosing a journal beyond OA options. These include considering the article license type, the archiving services available, the financial policies for review and publication, and the release requirements for data, code, and software. Responsibility for moving towards open hydrology lies with the author, editors, and reviewers. Reviewers can promote proper citing and acknowledgment of data and code sources by requesting that these be made publicly available when they are missing from the submitted paper. To this end, reviewers can start by checking whether the authors of the article adhere to the journal's open science standards. If this is not the case, the reviewer can indicate clearly in their review that the work does not comply and provide constructive feedback for how these standards can be met. If the journal does not have clearly defined open science standards, reviewers can request and provide steps on how authors can adhere to open science practices to ensure that the submitted work is reproducible. Likewise, reviewers can initiate discussions with the editor and highlight how the importance of clear open science standards provides guidance to authors and generally improves the quality, transparency, and reproducibility of submitted articles.

Articles that have not yet undergone peer review but that are published publicly (i.e., preprints) can be shared at any stage of the open hydrology project (Saia, 2019). Preprints are a good opportunity for authors to share and get feedback from a more diverse set of reviewers while retaining control of the research publication timeline (Schloss, 2017; Saia, 2019). Before posting a preprint, we suggest researchers check with their target journal about the acceptability of published preprints. Many journals will allow you to submit an article that has been posted as a preprint, but some will not. Visit Sherpa Romeo or the Journal Checker Tool (provided by cOAlition S) to find out about preprint policies, copyrights, and open access archiving policies from various publishers and journals.

Another important aspect related to OA publishing is the license attached to an article and its associated research materials. Creative Commons licenses (e.g., CC-BY) are widespread, but some publishers choose more restrictive versions, indicated by additions such as NC ("for noncommercial use") or ND ("No derivatives or adaptations of the work are permitted.") (Creative Commons About CC Licenses, 2019). ND licenses hamper re-use of the published work since extracting figures or tables from the pa- 
per is not allowed. Besides the article itself, it is important to ensure that data and code are licensed (i.e., a copyleft or non-copyleft license). A copyleft license type mandates that derivatives of the software and code apply the same licensing restrictions as the original work (Open Source Initiative FAQ). A non-copyleft license, or permissive license, allows for derivatives of the software to be licensed under other types (Open Source Initiative FAQ; Creative Commons FAQ, 2021). For software, we suggest the authors start by declaring a permissive license because it improves transparency and reduces downstream licensing conflicts. Developers should consider the impact of charging licensing fees or using closed licenses, which may lead to a lack of access for those that cannot afford licensing fees or time to negotiate access. However, software developers should be aware of upstream licenses and whether those may impact their ability to choose a particular open source license. Text, images, videos, photos, or other media created during or associated with a hydrologic project can be licensed using a CC-BY license to ensure creator attribution (i.e., the BY of CC-BY).

Data and code associated with an article must be cited in the article and published in a long-term repository, with a separate digital object identifier (DOI) and a permissive open source license (e.g., re3data). This facilitates citations and allows for re-use and modification of the work. To ensure that researchers providing software and data get properly credited for their efforts, third-party data or software used by others must be cited accordingly. Unlike data, source code for research software rarely requires much storage and can be shared quite easily (see Principle 3 ). The problematic aspect of software development is ensuring that it is available and usable for decades. Journals often allow software to be published as a Supplement, which is most suitable for scripts and Jupyter notebooks created specifically for a publication. More general-use software should be published and archived in a public repository with a separate DOI. One prime example is Zenodo - a free service for hosting data and software that offers long-term $(\sim 20$-year $)$ storage and integration with GitHub and that provides a DOI for each software version deposited there. These DOIs can be used as references in publications and clearly define the software version used.

\section{Summary and outlook}

Open, accessible, reusable, and reproducible hydrologic research will have the largest equitable impact on the scientific community and broader society. Funding agencies, publishers, and hydrologic organizations are increasingly requiring hydrologists to adopt open science practices, but not all are aware of the additional effort and time needed. Adopting open science practices can be a major lift for researchers, as these practices need to be implemented throughout the process, from the project design and budget generation to the final outputs and post-publication curation of data. We wrote "A Hydrologist's Guide to Open Science" to facilitate the transition to fully open science within hydrology, for hydrologists at the forefront of this movement and those transitioning their research to fully open science. This work introduces four guiding Open Hydrology Principles (Fig. 1) referring to each of the four main research stages: (1) research process and approach, (2) data collection and analysis, (3) code, software development, and use, and (4) publishing. For each principle, we provided actionable steps (i.e., the Open Hydrology Practical Guide) on how to become a more open hydrologist (summarized in Table 2).

Hydrologists intending to implement the advice given here will, undoubtedly, run into challenges along their path. We identified and addressed 12 challenges in five scenarios that cover various hydrology career stages (Appendix A). Researchers interested in open hydrology can use these scenarios to roleplay common challenges and brainstorm strategies with colleagues (e.g., in your lab or department's journal club) to overcome these challenges on their way to becoming an as-open-as-possible hydrologist.

While approaches and methods related to open science are in constant development, the Open Hydrology Principles will guide us in the future. The Open Hydrology Practical Guide is written based on currently available paradigms, tools, policies, and experiences; it will be updated and replaced by guidance as the state of hydrology and open science policies change. Therefore, we created https://open-hydrology. github.io (last access: 1 February 2022) - a living version of this article to build a supportive and collaborative open science community within the field of hydrology.

Open science makes research outcomes and processes accessible for inclusion in teaching and curriculum development. A movement parallel to open science is open education, which argues for and provides tools to share education materials and best practices freely and openly. While this was not the focus of this paper, we recognize the importance and feel that future work should support open education in hydrology and the broader geosciences.

Getting to the point where a majority of hydrologists participate in open hydrology will take time and effort. These efforts will be driven by individual hydrologists implementing openness as well as by organizational and governmental policies that incentivize open science. This step-by-step process must be regarded as a valuable contribution to hydrology and systemically supported by scientific institutions and beyond. Only then can the entire hydrology community really come together, build on one another's work, strengthen hydrologic knowledge, and maximize the benefits of hydrologic research to the whole of society. 


\section{Appendix A}

There are no "one-size-fits-all" open hydrology best practices because each project exists within a unique context of research inputs and outputs, institutional structures, and collaborators, each motivated by different incentives and policies in place. Challenges to practicing open hydrology may arise throughout the research process and may depend on the career stage of researchers. In general, challenges to practicing open hydrology revolve around socio-cultural, organizational, economic, technological, political, and legal themes that are listed in Table A1 (About FOSTER, 2021; Allen and Mehler, 2019). Socio-cultural challenges refer to a hydrologist's limited knowledge of, confidence in, and access to open hydrology practices and tools. Technological, organizational, and economic themes refer to challenges beyond the control of individual researchers trying to do open hydrology. For example, hydrologists may strive to do open research but be limited by unstable Internet connections (i.e., technical challenge), power to advocate for publishing their work openly (i.e., organizational), or lack of funds to pay for open access publication fees (i.e., economic). Note that only 3 out of 13 challenges are of a technical nature. This shows that the adoption of open science is (no longer) a primarily technical challenge.

Resolving obstacles to open hydrology takes know-how and persistence since challenges can be complex. To facilitate direct practice in addressing challenges to open hydrology, we present five scenarios and outline key discussion points and recommendations. Each scenario highlights a particular career stage and addresses specific challenges listed in Table A2. These five scenarios are inspired by active learning educational materials (Software Carpentry: Learner Profiles, 2021). Researchers interested in open hydrology can use these scenarios to roleplay common challenges and brainstorm strategies with colleagues (e.g., in your lab or department's journal club) to overcome these challenges. For each scenario, we encourage open hydrologists to ask (1) "What are the important challenges and themes highlighted in this scenario?" and (2) "How might I/we overcome these challenges as a lab group/department/institution/organization?" We encourage open hydrologists to suggest additional challenges and scenarios that we may have missed by contributing to the living document (https://open-hydrology.github.io, last access: 1 February 2022).

\section{Scenario A - knowledge of and support for practicing open hydrology}

Jaime is a PhD student studying the impacts of irrigation strategies on groundwater levels. Jaime recently saw the terms "open science", "open access", "preprints", and "open source software" used by hydrologists they follow on Twitter. No one in Jaime's lab/department has ever men- tioned these terms, and Jaime does not know where to go to learn more specifics or how to participate.

Knowing where to look, knowing how to find, and knowing how to use open science resources are fundamental skills of any successful open hydrologist and take time to learn. When knowledge of open hydrology resources and skills is accompanied by freely accessible tools (e.g., code repositories, tutorials) and supportive communities, it becomes easier and less overwhelming to pursue open science strategies. It can be especially difficult when researchers face compounding socio-cultural challenges like Jaime in Scenario A. As an early career scientist, Jaime's ability to practice open hydrology is hampered by their limited knowledge of open hydrology resources (Challenge no. 1, Table A1) and limited (local) support (Challenge no. 3, Table A1). As a result, Jaime may feel overwhelmed, uncertain, and anxious about practicing open hydrology.

It is important to recognize that anyone, regardless of career stage, can become an open hydrologist. On a personal level, self-study can be an effective first step to learning about open science principles and tools. Set aside time to read papers on reproducible research, version control, etc., and practice putting what you learn to use. You can also attend free online seminars (e.g., R-Ladies Global meet-ups) or listen to podcasts (Orion Open Science Podcasts, 2021; EOSC Podcast Special: Making Open Science FAIR For Researchers, 2021) to learn at your own pace. There are plenty of freely accessible resources on the web that explain basic open science practices (Hampton et al., 2015; Allen and Mehler, 2019). Another important option is to reach out to friends (including those on social media), mentors, institutional staff (e.g., librarians, data managers), and colleagues familiar with practicing open science for tips on what resources they found helpful and why. They may even be interested in giving an introductory seminar or facilitating a lab group discussion. It may also help to engage with other like-minded early career scientists during institutional or professional society meetings. This way you can learn from one another and support each other's open hydrology initiatives, like https://open-hydrology.github.io (last access: 1 February 2022).

\section{Scenario B - collaborator influence on practicing open hydrology}

Deniz is an established hydrologist working at a government agency and is co-advising a Master's student in ecohydrology at a nearby university. In a recent committee meeting, the Master's student asked Deniz to post a preprint of their paper after it is submitted to the journal for review. The Master's student also asked whether Deniz knew of places where they could post the dataset from their study upon acceptance to the journal. Deniz has an agency colleague with experience publishing datasets but was worried that preparing the datasets for publication might take the Master's student 
Table A1. List of common challenges that open hydrologists may experience.

\begin{tabular}{|c|c|c|}
\hline Number & $\begin{array}{l}\text { Challenge } \\
\text { (refer to Table A1) }\end{array}$ & Categories \\
\hline 1 & $\begin{array}{l}\text { Challenges surrounding navigating open hydrology resources, which may result in a } \\
\text { lack of confidence, fear of criticism, and decreased motivation to pursue open hydrol- } \\
\text { ogy. }\end{array}$ & Socio-cultural \\
\hline 2 & $\begin{array}{l}\text { Time spent practicing open hydrology is not supported, valued, or rewarded, and bene- } \\
\text { fits may not be felt. }\end{array}$ & Socio-cultural \\
\hline 3 & $\begin{array}{l}\text { Lack of community to provide technical and motivational support addressing differ- } \\
\text { ent experience and institutional levels (i.e., research group, departmental, institutional, } \\
\text { regional, global scale) }\end{array}$ & Socio-cultural \\
\hline 4 & $\begin{array}{l}\text { Lack of power to advocate for open hydrology practices, e.g., resistance from senior } \\
\text { colleagues and institutional policies }\end{array}$ & Socio-cultural, political \\
\hline 5 & $\begin{array}{l}\text { Unrecognized privileges within the research community (e.g., technologies, publica- } \\
\text { tions, limited access to funds) limit equitable participation in open hydrology, which } \\
\text { further exacerbates inequities and "gatekeeping". }\end{array}$ & Socio-cultural \\
\hline 6 & $\begin{array}{l}\text { Lack of proper acknowledgement or citations of open hydrology resources (e.g., open } \\
\text { data and code), which may result in limited sharing due to the fear of being scooped or } \\
\text { not getting credit for work. }\end{array}$ & Socio-cultural \\
\hline 7 & $\begin{array}{l}\text { Lack of incentive to publish iterations (i.e., lessons learned) in research approaches and } \\
\text { null and negative results }\end{array}$ & Socio-cultural \\
\hline 8 & Limited documentation and sustained maintenance of publicly available data, code, etc. & Technological \\
\hline 9 & $\begin{array}{l}\text { Limited access to technical resources and/or physical facilities that are required for prac- } \\
\text { ticing open hydrology (e.g., cloud computing, stable Internet connection, work com- } \\
\text { puter) }\end{array}$ & Technological \\
\hline 10 & Prohibition and/or restriction of open source software installation on work computers & $\begin{array}{l}\text { Technological, organizational, } \\
\text { political }\end{array}$ \\
\hline 11 & $\begin{array}{l}\text { Lack of and/or limited funds to afford the high cost of open access publishing, which } \\
\text { may depend on complex institutional, regional, national, and global open science fac- } \\
\text { tors. }\end{array}$ & $\begin{array}{l}\text { Organizational, economic, } \\
\text { political }\end{array}$ \\
\hline 12 & $\begin{array}{l}\text { Restrictions on practicing open hydrology imposed by public and private institutional } \\
\text { rules and national policies }\end{array}$ & Political, legal \\
\hline 13 & $\begin{array}{l}\text { Need to respect and honor privacy, data sovereignty, and data governance of stakehold- } \\
\text { ers and collaborators }\end{array}$ & Legal, political, socio-cultural \\
\hline
\end{tabular}

Table A2. Scenario summary table.

\begin{tabular}{lllll}
\hline Letter & Scenario title & Actor & Career level & Challenges \\
\hline A & Knowledge of and support for practicing open hydrology & Jaime & Early career student & No. 1, no. 3 \\
B & Collaborator influence on practicing open hydrology & Deniz & Established researcher & No. 2, no. 6, no. 12 \\
C & Respecting and upholding stakeholder interests & Alex & Principal investigator & No. 12, no. 13 \\
D & Cost of open publishing & Robin & Postdoc & No. 4, no. 11 \\
E & Promoting a culture of open hydrology & Dr. Hydro & Department head & No. 4, no. 5, no. 6, no. 9 \\
\hline
\end{tabular}


too much time. Also, Deniz needed to check whether it was against agency policy to publish the paper before it was peerreviewed. Not to mention, what if the non-peer-reviewed results were scooped by other scientists or used prematurely by decision-makers?

In Scenario B, a combination of socio-cultural, political, and legal challenges may come into play when practicing open hydrology at different career stages. Open hydrologists will likely encounter collaborators who are less supportive about practicing open hydrology. Limited enthusiasm may present itself throughout the research process, from sharing data and code to posting preprints and paying for open access fees, and more. In Scenario B, Deniz's concern may be that time spent documenting and publishing data will outweigh long-term benefits (Challenge no. 2, Table A1), like the increased research exposure and citations associated with open science. Fear of being scooped - when one researcher group publishes work before another doing similar work (Challenge no. 6, Table A1) - is a common reason for limited participation in open science (Laine, 2017). As Deniz supposes, research staff may also be subject to government agency policies that limit their ability to practice open hydrology (Challenge no. 12, Table A1).

Research supervisors and supervisees both play a critical role in the promotion and practice of open hydrology. If you are a supervisor, explicitly discuss and incorporate aspects of open hydrology into new, ongoing, and completed research collaborations to ensure research transparency. By keeping an open mind and candidly discussing practicing open hydrology when approached by your supervisee, a solution that addresses your and your supervisee's concerns and aspirations can be found. If you are a supervisee, provide your valid arguments for open hydrology while still being considerate of your supervisor's concerns and honoring potential policies limiting open practices. One point to address is that early publication of outputs is a protection against being scooped, as your contribution is documented with a date attached to its sharing. Another point to address can be highlighting the potential long-term impact of open hydrology on your career (Allen and Mehler, 2019). Another approach might be to ask established open hydrologists to discuss with you and your supervisor their points of hesitation. For both supervisors and supervisees, reflect on each aspect of your research pipeline and how each adheres to open hydrology principles. Start with small changes and sustainably build on your open hydrology practices with each new project (Allen and Mehler, 2019). Furthermore, advocate for policy changes and longterm perspectives that value open hydrology practices. Time and effort dedicated to making research more open is not a loss because it will benefit current and future research collaborators, stakeholders, and society.

\section{Scenario C - respecting stakeholder interests}

Alex is a principal investigator conducting a sociohydrology research project in collaboration with local stakeholders who hold diverse beliefs on a particular issue impacting the region. Alex has had in-depth conversations with these stakeholders, and all members of the project have agreed to participate in an anonymous survey that will assess their perspectives on the regional issue. In this project, Alex must protect personally identifying information when sharing results. Furthermore, Alex and the stakeholders have come to an agreement on specific data outputs and use cases that can be shared publicly; all other data and use cases are the property of the stakeholders.

Since an increasing amount of hydrology research is conducted in collaboration with stakeholders, it is important to respect the rights and requests of these stakeholders (Challenge no. 13, Table A1), maintain stakeholder privacy (Challenge no. 12, Table A1), and adhere to research sharing agreements. In Scenario C, Alex must navigate a combination of political, legal, and socio-cultural challenges when conducting transdisciplinary hydrology research alongside communities.

Open hydrologists can consider several strategies to uphold their commitment to transparency and reproducibility while respecting the rights and policies of their collaborators. Project leaders have a fundamental responsibility to spend time developing an open research plan with collaborators and stakeholders that describes public versus private research outputs, use cases, and what will be shared with whom and when. Importantly, all impacted community members must co-produce this open research plan with the research team and consent to data collection, analysis, and dissemination. You can look at standard privacy guidelines, including the General Data Protection Regulation (General Data Protection Regulation (GDPR), 2021) and data governance and data sovereignty principles (Carroll et al., 2020). Principle 2 discusses how to document decisions made and protocols around public research sharing so others can refer to this context and guidance can be found with the United Nations GEMStat program (GEMStat data protection declaration under the GDPR, 2021). You may be able to share anonymized data such as metadata that do not indicate water quality issues for a specific geographic region.

\section{Scenario D - cost of open publishing}

Robin recently defended their PhD thesis and started a postdoctoral researcher position. In their free time, Robin is finishing up an irrigation water management project that they worked on alongside agricultural producers during their PhD research. Robin will present these findings to agricultural producers during a virtual webinar and wants to publish these findings in an open access journal article so that it is easier for people outside academia to find and read. 
However, Robin does not have enough grant funds to cover the expensive open access fees and feels uncomfortable asking their postdoctoral advisor, who is in a different subhydrology field, for these funds.

Scenario D illustrates how distressing the lack of extra funds needed to pay open access publication fees is (Challenge no. 11, Table A1), which is a common concern when practicing open hydrology. This scenario can be exacerbated when early career open hydrologists, like Robin, are transitioning between positions and projects and/or have limited power and resources to advocate for covering the cost of these fees (Challenge no. 4, Table A1). This inability to cover the cost influences the impact of the research because open access publications tend to be cited more (Wang et al., 2015) and are assuredly accessible to research partners and the general public. Open access publishing is a common and effective starting point for practicing open hydrology. Beyond challenges posed by being early in one's career stage, economic, political, and organizational challenges may hamper efforts by researchers of all experience levels from developing countries.

To overcome the challenges outlined in Scenario D, established open hydrologists can start as early as possible in the research process to plan for open access publishing. The easiest solution is to look for an OA journal that does not charge an article processing cost (APC) to the authors or any of the authors' institutions. You can budget funds to cover the cost of these fees in a grant, use discretionary funds, or cost-share with co-authors. In some cases, researchers who work for government agencies can retain the copyrights to their publications. More specifically, journals have special provisions to allow them to share the journal-formatted paper without infringing on the journal's copyright laws. However, you should check the policies for each journal as the corresponding author may have to be from the government agency and/or several co-authors may also have to be from a government agency to qualify. In other cases, journals waive fees and/or discounts to researchers from certain countries or per individual requests. You can also check the journal website and publisher's policy to learn about your institution's or country's eligibility conditions. If you are an early career open hydrologist who was not present at the start of the research project, you can discuss the possibility of open access publishing with your supervisor. Some libraries and institutions have dedicated supplemental funds to support researchers who choose to publish their papers as open access. If all else fails, researchers typically can post a plain copy of the journal article on a non-for-profit preprint server (e.g., EarthArXiv). This can be done at any stage of paper preparation, but all corresponding authors need to agree to post the preprint.

\section{Scenario E - promoting a culture of open hydrology}

Dr. Hydro is the faculty chair of an environmental sciences department and is providing mentorship and departmental support (e.g., funding for open access and technology fees, honors to researchers doing open science) to several graduate students and faculty members in the department who have started organizing discussion groups and developing training materials to promote short- and long-term open science practices within their research groups. Some members of the department feel like this is a waste of time, but Dr. Hydro thinks these are important initiatives that will benefit the members of their department and beyond, especially in the long-term.

Unlike Scenarios A-D, Scenario E represents an example of a senior researcher supporting open hydrology efforts at their institute. Open science is a cultural movement, which ought to find deep roots in the hydrology community given the potential impact of our work on society. However, promoting a culture of open science requires individual- and community-based responsibility. We are each a part of a cultural shift towards open hydrology. At the individual level, researchers' roles in open hydrology are crucial and diverse. In Scenario E, Dr. Hydro strives to overcome socio-cultural, technological, and political challenges to promote open hydrology in their department, institution, and beyond. Specifically, Dr. Hydro uses their position (i.e., power) as a department chair to advocate for open hydrology practices (Challenge no. 4, Table A1), ensures that all members of the department have equitable opportunities for practicing open hydrology (Challenge nos. 5 and 9, Table A1), and promotes and honors community-driven open hydrology initiatives in the department (Challenge no. 6, Table A1). Although this might seem like a huge challenge at the beginning, Dr. Hydro is convinced that these efforts will not only benefit the hydrologists at their institute, but also ultimately the entire field of hydrology and society.

Researchers interested in practicing open hydrology can organize or attend regular seminars or journal clubs, while early to established researchers can learn about open science principles and ways to apply them to their work. Such a space can serve as a platform to discuss open hydrology and brainstorm solutions for common issues that are encountered. If you are a principal investigator of a research group, you can play an important role in promoting open hydrology by establishing guidelines for your trainees. Finally, students, staff, and faculty can all promote the use of open source software like R, Python, or QGIS for hydrology research and participate in local, regional, national, and global efforts to support open science.

Data availability. This paper contains a literature overview of the current state of "Open Science" related to hydrology and the author's views on how to proceed forward as a community. As such, 
other than the sources cited in the references, no data was used to produce this work.

Author contributions. All the authors contributed to the conceptualization of this article and participated in writing the original draft as well as draft review and editing. $\mathrm{CAH}$ administered this project, NDo created the Figure, and NDr created the GitHub repository and living version website.

Competing interests. One of the authors is a member of the editorial board of Hydrology and Earth System Sciences. The peerreview process was guided by an independent editor, and the authors also have no other competing interests to declare.

Disclaimer. Publisher's note: Copernicus Publications remains neutral with regard to jurisdictional claims in published maps and institutional affiliations.

Acknowledgements. We would like to thank the editor (Wouter Buytaert) and thoughtful reviewers (Francesca Pianosi, Koen Hufkens, Lina Stein, and Anonymous) who provided excellent feedback and helped shape the final version of this document. We would like to thank Lieke Melsen, Thorsten Wagener, and other colleagues who inspired this work, e.g. during the EGU GA 2019 PICO session HS1.2.7 Innovative methods to facilitate open science and data analysis in hydrology - from data collection in challenging environments to data sharing, visualization and modelling, for the initial discussions and inspiration to write this paper. There is no code or data associated with this article. Please endorse the Open Hydrology Principles, contribute to the open hydrology discussion, and access a living version (i.e., up-to-date version) of the Open Hydrology Principles and Practical Guide online at https://open-hydrology.github.io (last access: 1 February 2022).

Financial support. Andrea L. Popp is supported by the University of Oslo. Stanislaus J. Schymanski is supported by the Luxembourg National Research Fund (FNR) ATTRACT program (A16/SR/11254288). Tim van Emmerik is supported by the Veni Research Program River Plastic Monitoring Project (no. 18211), which is (partly) financed by the Dutch Research Council (NWO). Niels Drost and Rolf Hut are (partly) supported through the eWaterCycle project which is funded by the Netherlands eScience Center under file number 027.017.F01.

Review statement. This paper was edited by Wouter Buytaert and reviewed by Francesca Pianosi, Koen Hufkens, and one anonymous referee.

\section{References}

About FOSTER: About the FOSTER Portal, available at: https:// www.fosteropenscience.eu/about, last access: 19 March 2021.

Addor, N., Do, H. X., Alvarez-Garreton, C., Coxon, G., Fowler, K., and Mendoza, P. A.: Large-sample hydrology: recent progress, guidelines for new datasets and grand challenges, Hydrolog. Sci. J., 65, 712-725, https://doi.org/10.1080/02626667.2019.1683182, 2020.

Allen, C. and Mehler, D. M. A.: Open science challenges, benefits and tips in early career and beyond, PLOS Biol., 17, e3000246, https://doi.org/10.1371/journal.pbio.3000246, 2019.

American Geophysical Union (AGU) Position Statement on Data: Supporting Data as a World Heritage, available at: https://www.agu.org/Share-and-Advocate/Share/Policymakers/ Position-Statements/Position_Data, last access: 1 December 2021.

Añel, J. A., García-Rodríguez, M., and Rodeiro, J.: Current status on the need for improved accessibility to climate models code, Geosci. Model Dev., 14, 923-934, https://doi.org/10.5194/gmd14-923-2021, 2021.

Armeni, K., Brinkman, L., Carlsson, R., Eerland, A., Fijten, R., Fondberg, R., Heininga, V. E., Heunis, S., Koh, W. Q.., Masselink, M., Moran, N., Baoill, A. Ó., Sarafoglou, A., Schettino, A., Schwamm, H., Sjoerds, Z., Teperek, M., van den Akker, O. R., van't Veer, A., and Zurita-Milla, R.: Towards wide-scale adoption of open science practices: The role of open science communities, Sci. Publ. Policy, 48, 605-611, https://doi.org/10.1093/scipol/scab039, 2021.

Astagneau, P. C., Thirel, G., Delaigue, O., Guillaume, J. H. A., Parajka, J., Brauer, C. C., Viglione, A., Buytaert, W., and Beven, K. J.: Technical note: Hydrology modelling R packages - a unified analysis of models and practicalities from a user perspective, Hydrol. Earth Syst. Sci., 25, 3937-3973, https://doi.org/10.5194/hess-25-3937-2021, 2021.

Baker, L., Cristea, I. A., Errington, T. M., Jaśko, K., Lusoli, W., MacCallum, C. J., Parry, V., Pérignon, C., Šimko, T., and Winchester, C.: Reproducibility of scientific results in the EU: scoping report, edited by: Lusoli, W., European Commission, Luxembourg, 32 pp., 2020.

Beck, M. W., O'Hara, C., Stewart Lowndes, J. S., D. Mazor, R., Theroux, S., J. Gillett, D., Lane, B., and Gearheart, G.: The importance of open science for biological assessment of aquatic environments, PeerJ, 8, e9539, https://doi.org/10.7717/peerj.9539, 2020.

Blöschl, G., Bárdossy, A., Koutsoyiannis, D., Kundzewicz, Z. W., Littlewood, I., Montanari, A., and Savenije, H.: Joint Editorial-On the future of journal publications in hydrology, Hydrolog. Sci. J., 59, 955-958, https://doi.org/10.1080/02626667.2014.908041, 2014.

Blumenthal, M. B., Bell, M., del Corral, J., Cousin, R. and Khomyakov, I.: IRI Data Library: enhancing accessibility of climate knowledge, Earth Perspectives, 1, 19, https://doi.org/10.1186/2194-6434-1-19, 2014.

Borregaard, M. K. and Hart, E. M.: Towards a more reproducible ecology, Ecography, 39, 349-353, https://doi.org/10.1111/ecog.02493, 2016.

Bryan, J.: Excuse Me, Do You Have a Moment to Talk About Version Control?, Am. Stat., 72, 20-27, https://doi.org/10.1080/00031305.2017.1399928, 2018. 
Carroll, S. R., Garba, I., Figueroa-Rodríguez, O. L., Holbrook, J., Lovett, R., Materechera, S., Parsons, M., Raseroka, K., Rodriguez-Lonebear, D., Rowe, R., Sara, R., Walker, J. D., Anderson, J., and Hudson, M.: The CARE Principles for Indigenous Data Governance, Data Sci. J., 19, 43, https://doi.org/10.5334/dsj-2020-043, 2020.

Clark, M. P., Luce, C. H., AghaKouchak, A., Berghuijs, W., David, C. H., Duan, Q., Ge, S., van Meerveld, I., Zheng, C., Parlange, M. B., Tyler, S. W.: Open Science: Open Data, Open Models, ... and Open Publications?, Water Resour. Res., 57, e2020WR029480, https://doi.org/10.1029/2020WR029480, 2021.

Colavizza, G., Hrynaszkiewicz, I., Staden, I., Whitaker, K., and McGillivray, B.: The citation advantage of linking publications to research data, PLOS ONE, 15, e0230416, https://doi.org/10.1371/journal.pone.0230416, 2020.

Creative Commons About CC Licenses: About CC Licenses, available at: https://creativecommons.org/about/cclicenses/, last access: 1 December 2021.

Creative Commons FAQ: Creative Commons: FAQ, available at: https://creativecommons.org/faq/\#can-i-apply-a-creativecommons-license-to-software, last access: 1 December 2021.

Crochemore, L., Isberg, K., Pimentel, R., Pineda, L., Hasan, A., and Arheimer, B.: Lessons learnt from checking the quality of openly accessible river flow data worldwide, Hydrolog. Sci. J., 65, 699711, https://doi.org/10.1080/02626667.2019.1659509, 2020.

Cudennec, C., Lins, H., Uhlenbrook, S., and Arheimer, B.: Editorial - Towards FAIR and SQUARE hydrological data, Hydrolog. Sci. J., 65, 681-682, https://doi.org/10.1080/02626667.2020.1739397, 2020.

GEMStat Data protection declaration under the GDPR: UN environment programme, GEMStat, available at: https://gemstat.org/ contact/data-protection-gdpr/, last access: 21 July 2021.

David-Chavez, D. M. and Gavin, M. C.: A global assessment of Indigenous community engagement in climate research, Environ. Res. Lett., 13, 123005, https://doi.org/10.1088/17489326/aaf300, 2018.

de Vos, M. G., Hazeleger, W., Bari, D., Behrens, J., Bendoukha, S., Garcia-Marti, I., van Haren, R., Haupt, S. E., Hut, R., Jansson, F., Mueller, A., Neilley, P., van den Oord, G., Pelupessy, I., Ruti, P., Schultz, M. G., and Walton, J.: Open weather and climate science in the digital era, Geosci. Commun., 3, 191-201, https://doi.org/10.5194/gc-3-191-2020, 2020.

Dixon, H., Sandström, S., Cudennec, C., Lins, H. F., Abrate, T., Bérod, D., Chernov, I., Ravalitera, N., Sighomnou, D., and Teichert, F.: Intergovernmental cooperation for hydrometry - what, why and how?, Hydrolog. Sci. J., 1-15, https://doi.org/10.1080/02626667.2020.1764569, 2020.

Educational Resources for Hydrology and Water Resources: CUAHSI HydroShare, available at: https://www.hydroshare.org/ resource/148b1ce4e308427ebf58379d48a17b91/, last access: 21 July 2021.

Enemark, T., Peeters, L. J. M., Mallants, D., and Batelaan, O.: Hydrogeological conceptual model building and testing: A review, J. Hydrol., 569, 310-329, https://doi.org/10.1016/j.jhydrol.2018.12.007, 2019. $\begin{array}{ccccc}\text { EOSC } & \text { Podcast } & \text { Special: Making Open Sci- } \\ \text { ence } & \text { FAIR } & \text { For } & \text { Researchers, available at: }\end{array}$ https://www.eoscsecretariat.eu/news-opinion/ eosc-podcast-special-making-open-science-fair-researchers, last access: 21 July 2021.

Ferrari, T., Scardaci, D., and Andreozzi, S.: The Open Science Commons for the European Research Area, in: Earth Observation Open Science and Innovation, edited by: Mathieu, P.-P. and Aubrecht, C., Springer International Publishing, Cham, 43-67, https://doi.org/10.1007/978-3-319-65633-5_3, 2018.

Frith, U.: Fast Lane to Slow Science, Trends Cog. Sci., 24, 1-2, https://doi.org/10.1016/j.tics.2019.10.007, 2020.

General Data Protection Regulation (GDPR): Hydroshare, available at: https://gdpr-info.eu/, last access: 21 July 2021.

GitHub: Open-Environmental-Science/awesome-open-hydrology: available at: https:/github.com/Open-Environmental-Science/ awesome-open-hydrology, last access: 21 July 2021.

Gleeson, T.: A buffet of new resources for teaching hydrology and water resources!, EGU Blogs: Water Underground, 2020.

Hampton, S. E., Anderson, S. S., Bagby, S. C., Gries, C., Han, X., Hart, E. M., Jones, M. B., Lenhardt, W. C., MacDonald, A., Michener, W. K., Mudge, J., Pourmokhtarian, A., Schildhauer, M. P., Woo, K. H., and Zimmerman, N.: The Tao of open science for ecology, Ecosphere, 6, art120, https://doi.org/10.1890/ES1400402.1, 2015.

Hughes, D. A., Heal, K. V., and Leduc, C.: Improving the visibility of hydrological sciences from developing countries, Hydrolog. Sci. J., 59, 1627-1635, https://doi.org/10.1080/02626667.2014.938653, 2014.

Hutton, C., Wagener, T., Freer, J., Han, D., Duffy, C., and Arheimer, B.: Most computational hydrology is not reproducible, so is it really science?, Water Resour. Res., 52, 7548-7555, https://doi.org/10.1002/2016WR019285, 2016.

HydroShare: Hydroshare, available at: https://www.hydroshare.org/ landingPage/, last access: 21 July 2021.

Laine, H.: Afraid of Scooping - Case Study on Researcher Strategies against Fear of Scooping in the Context of Open Science, Data Sci. J., 16, 29, https://doi.org/10.5334/dsj-2017-029, 2017.

Lowndes, J. S. S., Best, B. D., Scarborough, C., Afflerbach, J. C., Frazier, M. R., O'Hara, C. C., Jiang, N., and Halpern, B. S.: Our path to better science in less time using open data science tools, Nature Ecol. Evol., 1, 1-7, https://doi.org/10.1038/s41559-0170160, 2017.

Melsen, L. A., Torfs, P. J. J. F., Uijlenhoet, R., and Teuling, A. J.: Comment on "Most computational hydrology is not reproducible, so is it really science?" by Christopher Hutton et al., Water Resour. Res., 53, 2568-2569, https://doi.org/10.1002/2016WR020208, 2017.

Michener, W. K.: Ecological data sharing, Ecol. Inform., 29, 33-44, https://doi.org/10.1016/j.ecoinf.2015.06.010, 2015.

Mislan, K. A. S., Heer, J. M., and White, E. P.: Elevating The Status of Code in Ecology, Trends Ecol. Evol., 31, 4-7, https://doi.org/10.1016/j.tree.2015.11.006, 2016.

Mukuyu, P., Lautze, J., Rieu-Clarke, A., Saruchera, D., and McCartney, M.: The devil's in the details: data exchange in transboundary waters, Water Int., 45, 884-900, https://doi.org/10.1080/02508060.2020.1850026, 2020.

Mwelwa, J., Boulton, G., Wafula, J. M., and Loucoubar, C.: Developing Open Science in Africa: Barriers, Solutions and Opportunities, CODATA, Data Sci. J., 19, 13, https://doi.org/10.5334/dsj2020-031, 2020 
Nüst, D., Sochat, V., Marwick, B., Eglen, S. J., Head, T., Hirst, T., and Evans, B. D.: Ten simple rules for writing Dockerfiles for reproducible data science, PLOS Comp. Bio., 16, e1008316, https://doi.org/10.1371/journal.pcbi.1008316, 2020.

OpenAIRE's Mission and Vision: OpenAIRE: Mission and Vision, available at: https://www.openaire.eu/mission-and-vision, last access: 19 March 2021.

Open Source Initiative FAQ: Open Source Initiative: FAQ, available at: https://opensource.org/faq, last access: 1 December 2021.

Orion Open Science Podcasts: Center for Genomic Regulation CRG: ORION Open Science Podcasts, available at: https://www.orion-openscience.eu/publications/ training-materials/201902/podcasts, last access: 21 July 2021.

Pecora, S. and Lins, H. F.: E-monitoring the nature of water, Hydrolog. Sci. J., 65, 683-698, https://doi.org/10.1080/02626667.2020.1724296, 2020.

Perez-Riverol, Y., Gatto, L., Wang, R., Sachsenberg, T., Uszkoreit, J., Leprevost, F. da V., Fufezan, C., Ternent, T., Eglen, S. J., Katz, D. S., Pollard, T. J., Konovalov, A., Flight, R. M., Blin, K., and Vizcaíno, J. A.: Ten Simple Rules for Taking Advantage of Git and GitHub, PLOS Comput. Bio., 12, e1004947, https://doi.org/10.1371/journal.pcbi.1004947, 2016

Pianosi, F., Sarrazin, F., and Wagener, T.: How successfully is open-source research software adopted? Results and implications of surveying the users of a sensitivity analysis toolbox, Environ. Modell. Softw., 124, 104579, https://doi.org/10.1016/j.envsoft.2019.104579, 2020.

Pinfield, S., Salter, J., and Bath, P. A.: The "total cost of publication" in a hybrid open-access environment: Institutional approaches to funding journal article-processing charges in combination with subscriptions, J. Assoc. Info. Sci. Tech., 67, 17511766, https://doi.org/10.1002/asi.23446, 2016.

Piwowar, H. A., Day, R. S., and Fridsma, D. B.: Sharing Detailed Research Data is Associated with Increased Citation Rate, PLOS ONE, 2, e308, https://doi.org/10.1371/journal.pone.0000308, 2007.

Powers, S. M. and Hampton, S. E.: Open science, reproducibility, and transparency in ecology, Ecol. Appl., 29, e01822, https://doi.org/10.1002/eap.1822, 2019.

Quinn, N., Blöschl, G., Bárdossy, A., Castellarin, A., Clark, M., Cudennec, C., Koutsoyiannis, D., Lall, U., Lichner, L., Parajka, J., Peters-Lidard, C. D., Sander, G., Savenije, H., Smettem, K., Vereecken, H., Viglione, A., Willems, P., Wood, A., Woods, R., Xu, C., and Zehe, E.: Invigorating Hydrological Research Through Journal Publications, Water Resour. Res., 56, 2018WR024053, https://doi.org/10.1029/2018WR024053, 2020

Ramachandran, R., Bugbee, K., and Murphy, K.: From Open Data to Open Science, Earth Space Sci., 8, e2020EA001562, https://doi.org/10.1029/2020EA001562, 2021.

Reichman, O. J., Jones, M. B., and Schildhauer, M. P.: Challenges and Opportunities of Open Data in Ecology, Science, 331, 703705, https://doi.org/10.1126/science.1197962, 2011.

Robinson, L. D., Cawthray, J. L., West, S. E., Bonn, A., and Ansine, J.: Ten principles of citizen science, in: Citizen science: Innovation in open science, society and policy, edited by: Hecker, S., Haklay, M., Bowser, A.,
Makuch, Z., Vogel, J., and Bonn, A., UCL Press, 27-40, https://doi.org/10.14324/111.9781787352339, 2018.

ropensci/Hydrology: CRAN Hydrology, available at: https://github. com/ropensci/Hydrology, last access: 1 December 2021.

Rosenberg, D. E. and Watkins, D. W.: New Policy to Specify Availability of Data, Models, and Code, J. Water Res. Pl-ASCE, 144, 01618001, https://doi.org/10.1061/(ASCE)WR.19435452.0000998, 2018.

Saia, S.: An Introduction to Preprints for Early Career Hydrologists, Young Hydrologic Society, available at: https://younghs.com/2019/05/20/ an-introduction-to-preprints-for-early-career-hydrologists/ (last access: 1 February 2022), 2019.

Schaefli, B.: Open teaching to navigate hydrology: how ready are we?, EGU Blogs: Hydrological Sciences, available at: https://blogs.egu.eu/divisions/hs/2021/02/24/ open-teaching-to-navigate-hydrology/ (last access: 1 February 2022), 2021.

Schloss, P. D.: Preprinting Microbiology, mBio, 8, mBio.00438-17, https://doi.org/10.1128/mBio.00438-17, 2017.

Slater, L. J., Thirel, G., Harrigan, S., Delaigue, O., Hurley, A., Khouakhi, A., Prosdocimi, I., Vitolo, C., and Smith, K.: Using $\mathrm{R}$ in hydrology: a review of recent developments and future directions, Hydrol. Earth Syst. Sci., 23, 2939-2963, https://doi.org/10.5194/hess-23-2939-2019, 2019.

Software Carpentry: Learner Profiles, available at: http: //software-carpentry.org/audience/, last access: 1 December 2021.

Sprenger, M.: When the students are gone: Transition to online teaching, EGU Blogs: Hydrological Sciences, https:// blogs.egu.eu/divisions/hs/2020/03/18/online-teaching/ (last access: 1 February 2022), 2020.

Stagge, J. H., Rosenberg, D. E., Abdallah, A. M., Akbar, H., Attallah, N. A., and James, R.: Assessing data availability and research reproducibility in hydrology and water resources, Sci. Data, 6, 190030, https://doi.org/10.1038/sdata.2019.30, 2019.

Stoudt, S., Vasquez, V. N., Martinez, C. C.: Principles for data analysis workflows, PLOS Comp. Bio., 17, e1008770, https://doi.org/10.1371/journal.pcbi.1008770, 2021.

Tai, T. C. and Robinson, J. P. W.: Enhancing Climate Change Research With Open Science, Front. Environ. Sci., 6, 115, https://doi.org/10.3389/fenvs.2018.00115, 2018.

The Carpentries: https://github.com/carpentries, last access: 1 February 2022.

Toribo-Flórez, D., Anneser, L., de Oliveira-Lopes, F. N., Pallandt, M., Tunn, I., and Windel, H.: Where Do Early Career Researchers Stand on Open Science Practices? A Survey Within the Max Planck Society, Front. Res. Metr. Anal., 5, 586992, https://doi.org/10.3389/frma.2020.586992, 2021.

Turner, B., Hill, D. J., and Caton, K.: Cracking "Open” Technology in Ecohydrology, in: Forest-Water Interactions, vol. 240, edited by: Levia, D. F., Carlyle-Moses, D. E., Iida, S., Michalzik, B., Nanko, K., and Tischer, A., Springer International Publishing, Cham, 3-28, https://doi.org/10.1007/978-3-030-26086-6_1, 2020.

UNESCO Science Commission adopts Open Science Recommendation: available at: https://council.science/current/news/unescoscience-commission-adopts-open-science-recommendation/ (last access: 1 December 2021). 
van den Ende, M., Bruhat, L., Funning, G., Gabriel, A., Hicks, S. P., Jolivet, R., Lecocq, T., and Rowe, C.: The Seismica Initiative: Creating a Diamond Open Access community journal for Seismology and Earthquake Science, EarthArXiv [preprint], https://doi.org/10.31223/X5304V, 2021.

Van Loon, A. F.: Online teaching in courses related to climate risk, drought, water resources and sustainability, Hydrological extremes@Amsterdam, 2020.

Viglione, A., Borga, M., Balabanis, P., and Blöschl, G.: Barriers to the exchange of hydrometeorological data in Europe: Results from a survey and implications for data policy, J. Hydrol., 394, 63-77, https://doi.org/10.1016/j.jhydrol.2010.03.023, 2010.

Venhuizen, G. J., Hut, R., Albers, C., Stoof, C. R., and Smeets, I.: Flooded by jargon: how the interpretation of water-related terms differs between hydrology experts and the general audience, Hydrol. Earth Syst. Sci., 23, 393-403, https://doi.org/10.5194/hess23-393-2019, 2019.

Wagener, T., Gleeson, T., Coxon, G., Hartmann, A., Howden, N., Pianosi, F., Rahman, S., Rosolem, R., Stein, L., and Woods, R.: On doing large-scale hydrology with Lions: Realising the value of perceptual models and knowledge accumulation, Hyd. Pro., 8, e14288, https://doi.org/10.1002/wat2.1550, 2021.

Walker, D. W., Smigaj, M., and Tani, M.: The benefits and negative impacts of citizen science applications to water as experienced by participants and communities, WIREs Water, 8, e1488, https://doi.org/10.1002/wat2.1488, 2021.

Walter, M., Kukutai, T., Carroll, S. R., and Rodriguez-Lonebear, D. (Eds.): Indigenous Data Sovereignty and Policy, 1st edn., Routledge, London, 244 pp., 2020.

Wang, X., Liu, C., Mao, W., and Fang, Z.: The open access advantage considering citation, article usage and social media attention, Scientometrics, 103, 555-564, https://doi.org/10.1007/s11192-015-1547-0, 2015.

Wilkinson, M. D., Dumontier, M., Aalbersberg, Ij. J., Appleton, G., Axton, M., Baak, A., Blomberg, N., Boiten, J.-W., da Silva Santos, L. B., Bourne, P. E., Bouwman, J., Brookes, A. J., Clark, T., Crosas, M., Dillo, I., Dumon, O., Edmunds, S., Evelo, C. T., Finkers, R., Gonzalez-Beltran, A., Gray, A. J. G., Groth, P., Goble, C., Grethe, J. S., Heringa, J., 't Hoen, P. A. C., Hooft, R., Kuhn, T., Kok, R., Kok, J., Lusher, S. J., Martone, M. E., Mons, A., Packer, A. L., Persson, B., Rocca-Serra, P., Roos, M., van Schaik, R., Sansone, S.-A., Schultes, E., Sengstag, T., Slater, T., Strawn, G., Swertz, M. A., Thompson, M., van der Lei, J., van Mulligen, E., Velterop, J., Waagmeester, A., Wittenburg, P., Wolstencroft, K., Zhao, J., and Mons, B.: The FAIR Guiding Principles for scientific data management and stewardship, Sci. Data, 3, 160018, https://doi.org/10.1038/sdata.2016.18, 2016.
Wittman, J. T., Aukema, B. H.: A Guide and Toolbox to Replicability and Open Science in Entomology, J. Insect Sci., 20, 1-9, https://doi.org/10.1093/jisesa/ieaa036, 2010.

WMO Unified Data Policy Resolution: WMO Unified Data Policy Resolution, available at: https: //public.wmo.int/en/our-mandate/what-we-do/observations/ Unified-WMO-Data-Policy-Resolution, last access: 1 December 2021.

Young Hydrologic Society (YHS): YHS community GitHub organisation account, available at: https://github.com/hydrosoc, last access: 21 July 2021.

Zipper, S. C., Stack Whitney, K., Deines, J. M., Befus, K. M., Bhatia, U., Albers, S. J., Beecher, J., Brelsford, C., Garcia, M., Gleeson, T., O'Donnell, F., Resnik, D., and Schlager, E.: Balancing Open Science and Data Privacy in the Water Sciences, Water Resour. Res., 55, 5202-5211, https://doi.org/10.1029/2019WR025080, 2019.

Zuiderwijk, A. and Hinnant, C. C.: Open data policy-making: A review of the state-of-the-art and an emerging research agenda: Introduction to a selection of open data policymaking papers from dg.o2018, Information Polity, 24, 117-129, https://doi.org/10.3233/IP-190160, 2019.

Zuiderwijk, A., Shinde, R., and Jeng, W.: What drives and inhibits researchers to share and use open research data? A systematic literature review to analyze factors influencing open research data adoption, PLOS ONE, 15, e0239283, https://doi.org/10.1371/journal.pone.0239283, 2020. 